\title{
高分子溶液及び微粒子含有高分子溶液の伸長粘度の測定
}

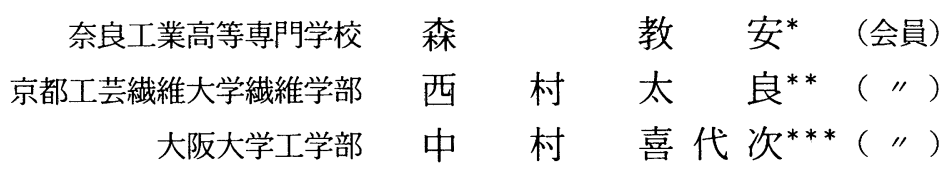

\section{Measurement of the Extensional Viscosity for Polymer Solutions and of Fine Particle Containing Polymer Solutions}

\author{
Noriyasu Mori*, Taro Nisimura** and Kiyoji Nakamura*** \\ *Nara National College of Technology, Yamatokoriyama, Nara. \\ **Department of Polymer Engineering, Kyoto Institute of \\ Technology, Sakyo-ku, kyoto. \\ ${ }^{* * *}$ Department of Mechanical Engineering, Osaka University, \\ Suita, Osaka.
}

\begin{abstract}
We use the spin line method, which is developed by Jones et al., to measure the extensional viscosity of polymer solutions and suspensions of fine particles in polymer solutions. From the velocity profiles obtained it is found that a uniaxial extensional flow is nearly attained in this experiment. We show that all the solutions of PAA are tension-thickening and the extensional viscosity in the suspensions is affected by the concentrations of both polymer and suspended particle.

(Received April 3, 1990)

\section{摘 要}

目的 高分子溶液及び微粒子含有高分子溶液の伸長粘度をスピンラインレオメーターの原理を用い測定し，高分子溶液の濃 度と伸長粘度の関係及び伸長粘度に及ぼす微粒子の影響について調べる。

成果 PAA 水溶液及び微粒子含有PAA 水溶液では, 広い区間で一軸伸長流れに近い速度分布が得られた。伸長粘度につい ては，本実験のすべての濃度において tension-thickening 性が見られ，さらに，微粒子の含有率が大きくなると大きな影響を 受けることが明らかになった。

(平成 2 年 4 月 3 日受理)
\end{abstract}

\section{1. 緒 言}

高分子溶液や融液などの物性を調べるとき，ずり 流れにおける粘度と法線応力差, あるいは, 動的粘 度と動的弾性率などの測定を行うことが多い.そし て，従来はこれらの物性をむとに流れの解析ん行っ てきた。しかし，紡系工程における流れは，明らか に一軸伸長流れであり，又，急激な流路における流
れも伸長流れの要素を強く含んでいると考えられ る. 最近, Debbaut ら ${ }^{1}$ は, 急絞り流路での流れの数 值計算で, 一般化ニュートン流体モデルとマックス ウェルモデルの粘度関数に伸長速度の影響を取り入 れ，ずり流れにおいて第一法線応力差が零である場 合でも大きな渦の発生が得られることを示した。こ のように，急絞り流路での流れなどのように伸長流 れを含んでいるときには，高分子流体の構成式の選 
択において，構成式の持っている伸長粘度特性を考 慮することが重要であると思われる。

高分子融液の伸長粘度は, 円筒状の試料の両端を 保持し引っ張ることにより一軸伸長流れを発生させ る方法で測定されている は, 融液のような方法では測定できず，オープン・ サイフォン法4), スピンライン法5), 対向ジェット法6) や急絞り流路を用いる方法》などが提案されてい る.しかし，いまのところどの方法に打いても，流 れをうまくコントロールすることができないことな ど多くの問題点を抱えており, さらに, 多くの研究 が待たれている.

本研究では, 種々の流体に対して測定が可能と思 われるスピンラインレオメーターの原理を用い, 高 分子溶液の伸長粘度の測定を行った。ささらに，粒子 や繊維の懸濁液に対しての今後の適用を考え, アル ミナの微粒子を含有した高分子溶液についても測定 を行った。

\section{2. スピンラインレオメーターの原理 と実験装置}

\section{1 伸長粘度の測定原理}

高分子溶液の伸長粘度の測定においては，一定の 伸長速度を持つ流れ場を実現させることは困難であ る. そこで, 図 1 に示す伸長流れに対して, Jones ら゙は，次式により平均伸長率を与えた。

$$
\dot{\varepsilon}=\frac{4 Q}{\pi L}\left(\frac{1}{D_{L}^{2}}-\frac{1}{D_{0}^{2}}\right)
$$

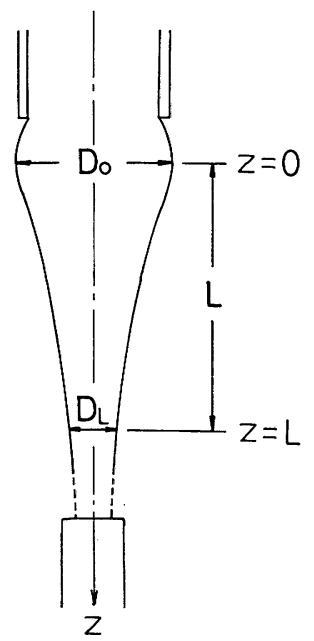

Fig. 1 Extensional flow in a spin line rheometer.
ここで, $Q:$ 体積流量, $L:$ 測定区間距離, $D_{L}: z=L$ での溶液径， $D_{0}$ : 溶液最大径である (図 1 参照).

又, Jones らと同様に溶液に働く表面力を無視する と, 平均伸長応力は, 次式で与えられる.

$$
T=\frac{4}{\pi D_{A V}{ }^{2}}\left(F_{N}+F_{I}-F_{G}\right)
$$

ここで, $D_{A V}$ : 溶液平均径, $F_{N}$ ：ノズル出口での外 力, $F_{l}$ : 溶液の慣性力, $F_{G}$ : 溶液に働く重力で,

$$
\begin{aligned}
& D_{A V}=\left(D_{L}+D_{O}\right) / 2 \\
& F_{G}=\int_{0}^{L} \rho g A d z \\
& F_{I}=G\left(V_{L}-V_{0}\right)
\end{aligned}
$$

である.ただし, $\rho:$ 溶液密度, $g$ : 重力加速度, $A:$ 溶 液断面積, $G$ : 質量流量, $V_{L}: z=L$ での流速, $V_{0}: z$ $=0$ での流速とする.これらの式から, 平均伸長率と 平均伸長応力が得られると, 伸長粘度 $\eta_{E}$ は次式で与 えられる。

$$
\eta_{E}=T / \dot{\varepsilon}
$$

\section{2 伸長粘度測定装置}

図 2 に伸長粘度測定装置の概略を示す，溶液夕ン ク (1)の供試溶液は空気圧によりステンレスパイプ(3) 内に送られ, 内径 $1.93 \mathrm{~mm}$ のノズル(5)より空気中 に流出する. 流出した溶液は, 真空ポンプにより負 圧となっている吸引用タンクの吸引口に吸い込ま れ，ノズルとの間に伸長流れを発生する。なお，吸 引用タンクの吸引口は, ノズルの鉛直下方に位置で きるように微動装置(7)に取り付けられている，ステ ンレスパイプはノズル側を自由端とした片持梁とな っており，ノズル出口における伸長力 $F_{N}$ を測定す るために，ノズル側より約 $45 \mathrm{~mm}$ 離れた位置で, 電子天科(4)と接続されている。 そこで, 電子天科の

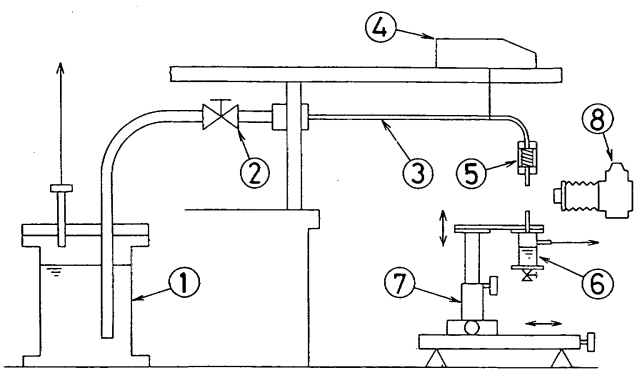

Fig. 2 Schematic diagram of the spin line rheometer.

(1) Reservoir, (2) Valve, (3) Delivery pipe, (4) Electrobalance, (5) Nozzle, (6) Suction tank, (7) Movable platform, (8) Camera. 
読みからノズル出口での伸長力を求めるために， あ らかじめ実験前に補正を行った，又，溶液の伸長流 れの輪郭は，カメラにより写真撮影し，デジタイザ 一とパーソナルコンピューターによりデータ処理を 行った。なお，本実験はすべて，液温が $20 \sim 22^{\circ} \mathrm{C}$ の範囲で行われている.

\section{3 供試溶液の粘度}

本実験では，ニュートン流体としてグリセリン を，そして，高分子溶液としてポリアクリルアミド (SEPARAN AP- $30-E$, DOW CHEMICAL COMPANY, 以後 PAA と略す）水溶液を用いた。, PAA 水溶液に含有させる微粒子として平均粒径が 約 $15 \mu \mathrm{m}$ のアルミナ粉末（第 1 メテコ(株製溶射用粉

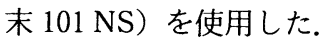

まず，供試溶液の粘度を求めるために，細管（半 径 $R=0.83 \mathrm{~mm}$, 長さ $500 \mathrm{~mm}$ ）を用い, 圧力損失 の測定を行った。図 3 に各種溶液の測定結果を示 す.ただし，図中の $\phi$ はアルルナ粉末の含有率を体 積分率により表したもので，本実験では $20 \%$ と $30 \%$ の 2 種類とした. 圧力損失 $\Delta P$ と流量 $Q$ の関 係は, すべて，両対数グラフ上で直線関係となって いる。 そこで, 溶液の粘度に次式のべき乗則モデル を採用した。

$$
\eta=K \dot{\gamma}^{n-1}
$$

ただし， $\eta$ は粘度， $\dot{\gamma}$ はずり速度， $K, n$ は定数であ る. 粘度がべき乗則モデルで与えられる流体の円管 内における圧力損失之流量の関係は,

$$
\log \left(\frac{R \Delta P}{2 L}\right)=n \cdot \log \left(\frac{4 Q}{\pi R^{3}}\right)+\log \left[K\left\{\frac{(3 n+1)}{4 n}\right\}^{n}\right]
$$

で表される.ただし， $R$ は円管半径， $\Delta P$ は距離 $L$ 間

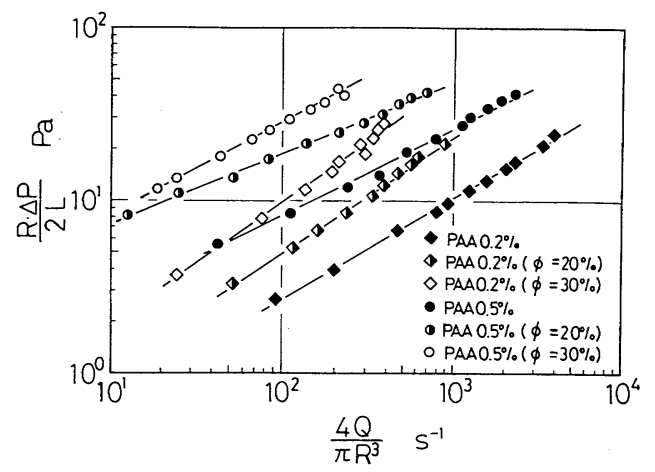

Fig. 3 Variations of wall shear stress with $4 Q$ / $\pi R^{3}$ obtained from capillary measurements.
Table 1 The power-law constants, $\mathrm{K}$ and $\mathrm{n}$, for test fluids.

\begin{tabular}{l|c|c}
\hline \hline Solution & $\mathrm{K} \mathrm{Pa} \cdot \mathrm{s}^{n}$ & $\mathrm{n}$ \\
\hline PAA 0.2\% & 0.157 & 0.593 \\
\hline PAA 0.2\% ( $\phi=20 \mathrm{vol} \%)$ & 0.200 & 0.681 \\
\hline PAA 0.2\% $(\phi=30 \mathrm{vol} \%)$ & 0.323 & 0.728 \\
\hline PAA 0.5\% & 0.709 & 0.510 \\
\hline PAA 0.5\% $(\phi=20 \mathrm{vol} \%)$ & 2.44 & 0.417 \\
\hline PAA 0.5\% $(\phi=30 \mathrm{vol} \%)$ & 2.11 & 0.543 \\
\hline
\end{tabular}

の圧力損失である．ここでは，(8)式を測定値に適用 し，各溶液に対する $K$ と $n$ を求めた。

その結果を表 1 に示す. PAA 水溶液では, 濃度が 高くなるほど $n$ の值が小さくなり, shear-thinning 性が強くなることが分かる. 又, アルミナの微 粒子を PAA 水溶液に含有させた場合には，PAA $0.2 \%$ 水溶液では, 含有率が大きいほど $n$ の值は大 きくなるが, PAA 0.5\% 水溶液では, $20 \%$ の含有率 で，水溶液そのものより $n$ の值が小さくなるという 結果を得た. 従来, 行われたガラスビーズを含有さ せた高分子融液 ${ }^{8)}$ や濃厚溶液に対する粘度測定 ${ }^{9}$ で は，含有率が大きくなるほど， $n$ の値は小さくなる という結果を得ており, 本実験の結果と異なる. 本 実験では, PAA $0.2 \%, 0.5 \%$ と比較的低濃度で低粘 度の溶液であるので, それが, 両者の結果の違いと なったものと考えられる。

\section{3. 伸長粘度の測定結果}

\section{1 溶液の速度分布}

本実験の流れ場は，流れ方向に速度勾配が一定で ある一軸伸長流れとなっていることが理想的であ る. しかし，高分子溶液などの流動性の強い流体で は，伸長流れにおいて流れ場をコントロールするこ とは困難である，そこで，伸長粘度の測定に当たり， まず溶液の $z$ 方向流速 $V$ の $z$ 方向の分布について 検討した。

図 4 にグリセリンの流速 $V$ の変化を，図 5 に PAA $0.5 \%$ 水溶液と微粒子含有高分子溶液の流速 $V$ の変化を示す。ただし, 流速 $V$ は実験により得ら れた溶液フィラメントの直径 $D$ の測定値を用い,

$$
V=4 Q /\left(\pi D^{2}\right)
$$

より計算した，グリセリンでは，伸長力が小さいた めに溶液のフィラメントを長くすることができなか った. そのために，ノズル出口 $(z=0)$ の直後を除 


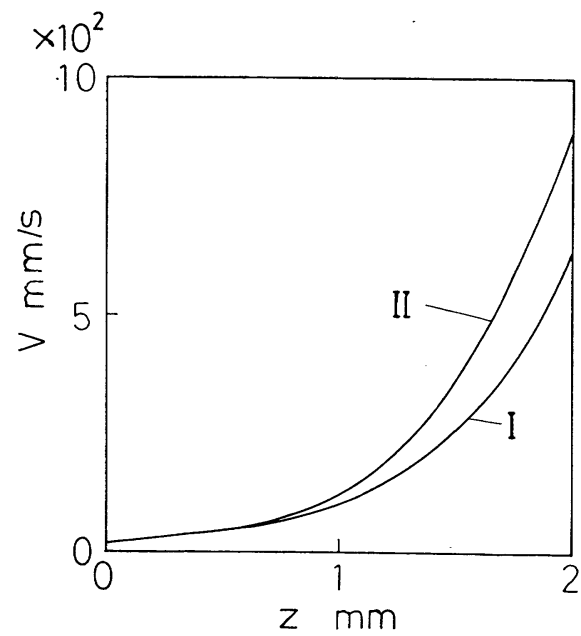

Fig. 4 Velocity profiles along the fluid spin line for glycerin. Flow rate and measured force at nozzle exit for the experiments are : I $G=0.56 \times 10^{-4} \mathrm{~kg} / \mathrm{s}, F_{N}=2.16 \times 10^{-4} \mathrm{~N}$, and II $G=0.40 \times 10^{-4} \mathrm{~kg} / \mathrm{s} . \quad F_{N}=2.07 \times$ $10^{-4} \mathrm{~N}$.

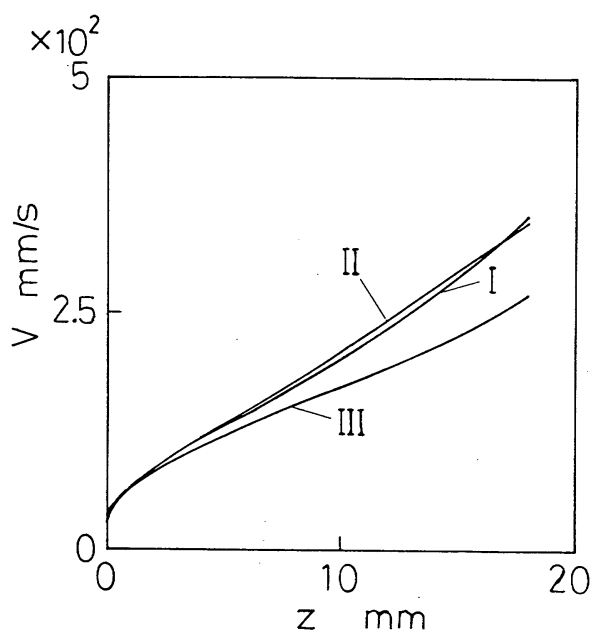

Fig. 5 Velocity profiles along the fluid spin line for a $0.5 \%$ solution of PAA and suspensions of aluminum oxide particles in it. The experimental conditions are : I $\phi=$ $0 \%, \quad G=0.107 \times 10^{-3} \mathrm{~kg} / \mathrm{s}, F_{N}=6.23 \times$ $10^{-4} \mathrm{~N}$, II $\phi=20 \%, G=0.095 \times 10^{-3} \mathrm{~kg} / \mathrm{s}$, $F_{N}=7.06 \times 10^{-4} \mathrm{~N}$ and III $\phi=30 \%, G=$ $0.111 \times 10^{-3} \mathrm{~kg} / \mathrm{s}, F_{N}=1.34 \times 10^{-4} N$.

いて流速は直線的に変化しておらず，正確には一軸 伸長流れとなっていない，それに対して PAA 0.5\% 水溶液の場合には, ノズル出口の直後を除いて, か なり長い区間にわたり流速は直線的に変化してお り, 一軸伸長流れに近い速度分布となっている。

\section{2 伸長粘度}

グリセリンのようなニュートン流体では, 一軸伸 長流れにおいて, 伸長粘度 $\eta_{E}$ がずり粘度 $\eta$ の 3 倍 になることが, Trouton ${ }^{10)} に よ り$ 示されている. 図 6 にグリセリンに対する測定結果を示す。ただし， 前述のように, グリセリンの速度分布は, ノズル出 口付近しか直線的に変化していないので, 伸長粘度 の算出に当たってはこの区間を使った。伸長粘度 は, ばらつきはあるものの一定値を示し, その值も ずり粘度の約 3 倍であり, Trouton の結果と一致し た.

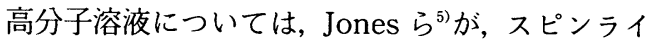
ンレオメーターにより PAA (E 10, Allied Colloids Ltd.) 水溶液の伸長粘度を測定したが, その濃度は, $2 \%, 2.5 \%$ 及び $3 \%$ 之高濃度である. 彼らの測定 值は, かなりばらつきが大きいが, どの濃度の場合 でも, 伸長速度が増加すると伸長粘度が増加する， いわゆる tension-thickening 性を示した。本実験 でも同じようにPAA 水溶液を使用したが，その濃 度は $1 \%, 0.5 \%$ 及び $0.2 \%$ であり, Jones らと比べ て低濃度で低粘度の溶液である. 図 7 に PAA $1 \%, 0.5 \%$ 及び $0.2 \%$ 水溶液の伸長粘度を示す. 濃 度が高くなるほど, 同じ伸長速度に対して伸長粘度 は大きくなっているが, どの濃度でも顕著な tension-thickening 性を示している.

次に, 微粒子含有高分子溶液の伸長粘度を測定 し，伸長粘度に対する微粒子の影響を検討した，図 8 , 図 9 に測定結果を示す。微粒子含有 PAA $0.5 \%$

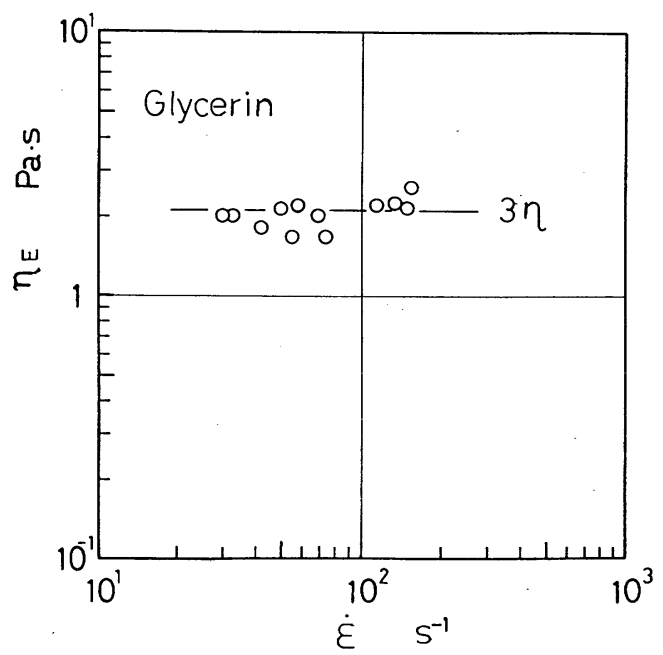

Fig. 6 Extensional viscosity data for glycerin. 


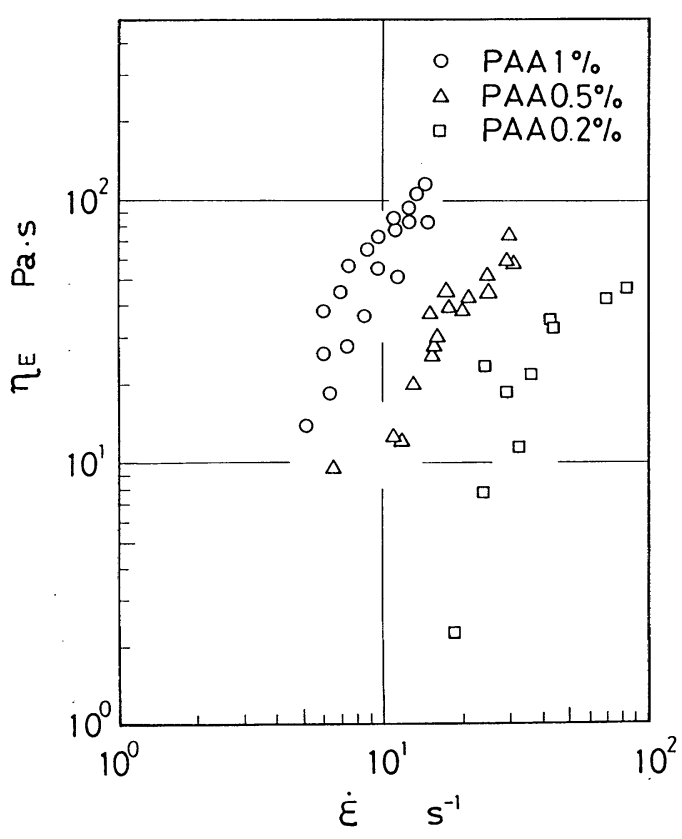

Fig. 7 Dependence of extensional viscosity on polymer concentration of PAA.

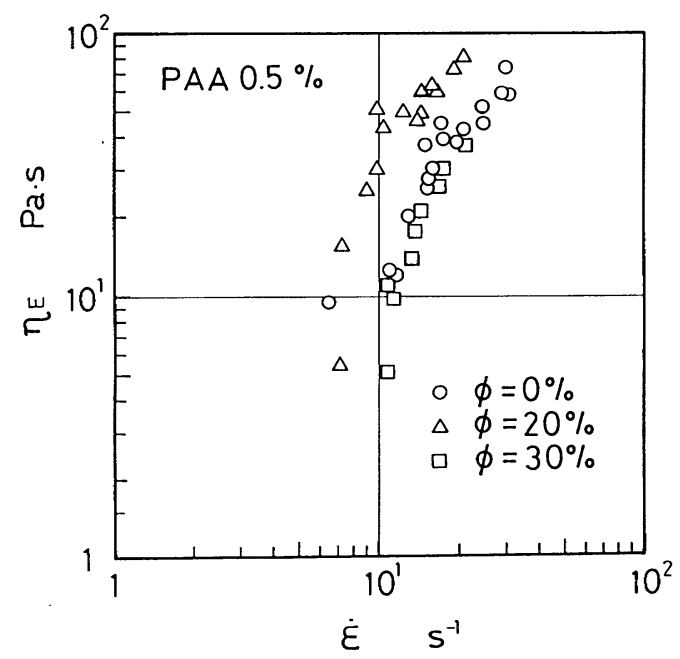

Fig. 8 Dependence of extensional viscosity on solids concentration for the $0.5 \%$ solution of PAA.

水溶液の場合には, $\phi=20 \%$ の溶液の方が，微粒子 の入っていない溶液よりも伸長粘度が大きくなって いる。しかし， $\phi=30 \%$ の溶液では逆にすこし小さ くなっている。このことは，PAA 0.5\% 水溶液とそ の微粒子含有高分子溶液のずり粘度における指数 $n$ の，微粒子含有率に対する変化に対応しているよう に思われる. 即ち， $\phi=20 \%$ の溶液ではずり粘度に

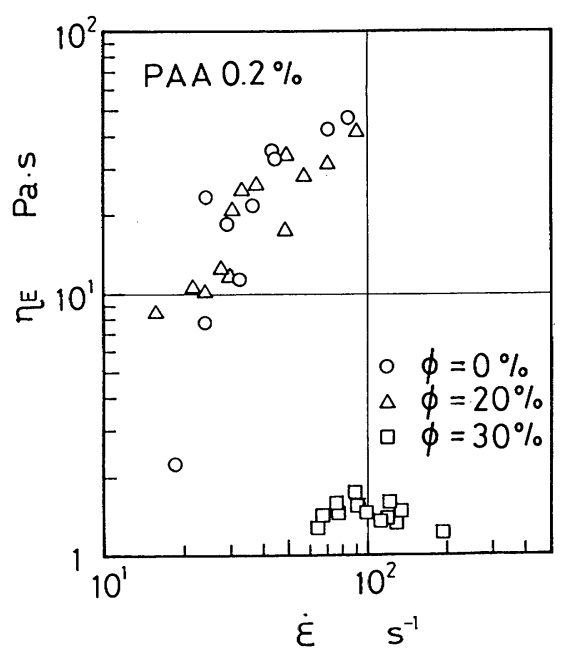

Fig. 9 Dependence of extensional viscosity on solids concentoation for the $0.2 \%$ solution of PAA.

おいて shear-thinning 性が強くなるとともに伸長 粘度の增加が見られ，そして $\phi=30 \%$ の溶液では shear-thinning 性が弱くなるとともに伸長粘度の 減少が見られる。一方, 微粒子含有 PAA $0.2 \%$ 水溶 液の場合には, $\phi=20 \%$ の溶液において伸長速度の 小さいところで伸長粘度が PAA $0.2 \%$ 水溶液より 大きくなっているが，デー夕のばらつきもあり全体 的にはあまり違いがないように思われる。しかし， $\phi=30 \%$ の溶液では伸長粘度は減少し，さらに， tension-thickening 性む見られない.このように, 微粒子の含有率が大きくなると高分子溶液の伸長粘 度に大きく影響することが分かる. 又, 高分子溶液 の濃度によって影響の現れかたに違いがあるように 思われる. しかし，本実験では，微粒子の形状や含 有率の影響についての系統的な実験を行っていない ので，伸長粘度に対する微粒子の影響については今 後詳細に解明していく必要がある.

ところで，伸長粘度とずり粘度との関連を調べる ため，次式で示されるように伸長粘度とずり粘度の 比（Trouton-ratio $T_{R}$ ) をとり，その值により伸長 粘度を議論することがある.

$$
T_{R}=\frac{\eta_{E}(\dot{\varepsilon})}{\eta(\sqrt{3} \dot{\varepsilon})}
$$

ニュートン流体の場合には，前述のように $T_{R}=3$ であることが知られている。図10に Trouton-ratio と平均伸長率の関係を示す.PAA 水溶液では, Trouton-ratio は, 濃度の高いものほど大きくなっ 


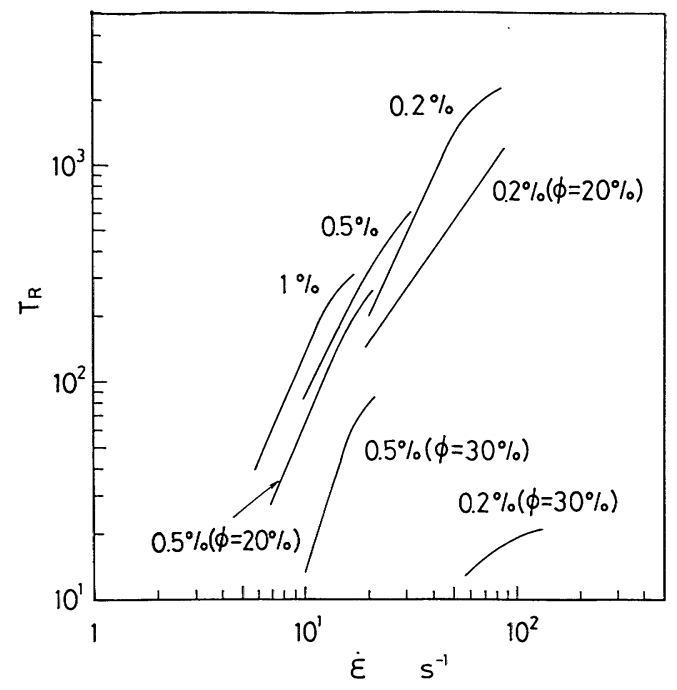

Fig. 10 Trouton ratios for the test fluids.

ている. 又, 微粒子含有 PAA 水溶液の場合には, 伸 長粘度のときと異なり， $\phi=20 \%, 30 \%$ いずれの場 合においても PAA 水溶液よりも Trouton-ratio は 小さくなっている. 特に, PAA $0.2 \%(\phi=30 \%)$ 水 溶液の場合には，著しい減少がみられ，微粒子によ り高分子の特性が抑制されているように思われる。

\section{4. 結言}

スピンラインレオメーターの原理を用いて, $\mathrm{PAA}$ 水溶液及び微粒子含有 PAA 水溶液の伸長粘 度の測定を行った。 その結果，次のようなことが明 らかとなった。

1) PAA 水溶液及び微粒子含有 PAA 水溶液では,
ノズル出口付近を除いてかなり広い区間で速度分 布は一軸伸長流れに近い分布となっている.

2) PAA 水溶液の伸長粘度は, 顕著な tensionthickening 性を示す。

3 ）本実験の含有率では，伸長粘度に及ぼす微粒子 の影響は大きい. 又, Trouton-ratio については, 微粒子含有率の大きい方が小さくなった。

終わりに，本研究を遂行するに当たり，奈良工業 高等専門学校の卒研生であった木曽智, 枝ふづきの 両氏及び大阪大学の学部学生であった大原 一氏に 多大の援助を賜ったことを記し，感謝の意を表しま す.

\section{参考文献}

1) D. Debbaut and M. J. Crochet ; J. Non-Newtonian Fluid Mech., 30, 169 (1988)

2) J. Meissner; Rheol. Acta, 10, 230 (1971)

3) H. Munstedt; J. Rheol., 23, 421 (1979)

4) M. Moan and A. Magueur ; J. Non-Newtonian Fluid Mech., 30, 343 (1988)

5) D. M. Jones, K. Walters, and P. R. Williams; Rheol. Acta, 26, 20 (1987)

6) G. G. Fuller, C. A. Cathey, B. Hubbard, and B. E. Zebrowski ; J. Rheol., 31, 235 (1987)

7) D. M. Binding and K. Walters; J. Non-Newtonian Fluid Mech., 30, 233 (1988)

8) D. L. Faulkner and L. R. Schmidt ; Polym. Eng. Sci., 17, 657 (1977)

9) L. Nicodemo, L. Nicolais, and R. F. Landel ; Chem. Eng. Sci., 29, 729 (1974)

10) F. T. Trouton; Proc. Roy. Soc. Lond., Ser. A77, 426 (1906) 